\title{
Barriers to Participation in Learning Management Systems in Saudi Arabian Universities
}

\author{
Abdullah Alenezi iD \\ Educational Technology Department, Northern Borders University, 7276 Old Airport, Arar 73312-5079, Saudi Arabia \\ Correspondence should be addressed to Abdullah Alenezi; abdullah.a.alenezi@nbu.edu.sa
}

Received 1 December 2017; Revised 31 March 2018; Accepted 8 April 2018; Published 6 May 2018

Academic Editor: Yi-Shun Wang

Copyright (C) 2018 Abdullah Alenezi. This is an open access article distributed under the Creative Commons Attribution License, which permits unrestricted use, distribution, and reproduction in any medium, provided the original work is properly cited.

This study was designed to identify various barriers that have hindered the adoption of LMSs in Saudi Arabian universities. Learning management systems (LMSs) have been adopted in many learning institutions because of their functionalities and applications to improve pedagogy. Universities have been encouraged to use LMSs to enhance the collaborative working environment among students and between the students and their instructors. This study was done by administering 150 questionnaires to students in three universities in Saudi Arabia. Findings from the study revealed that the main barriers to the use of LMSs were inadequate technical support by the universities, negative attitude toward technology, and inadequate training on the LMS platforms. Minor barriers identified include poor Internet access and networking, limited infrastructure to support the LMS, lack of hardware and software to run the LMS, and challenges in English language proficiency.

\section{Introduction}

Computer technology in educational systems goes back to decades during the "information revolution." In the 19th century, the "teaching machine," a special-purpose electromechanical machine, was used to teach students. This device displayed the instructional material for students, making information perception easier and more efficient. The origin of the learning management system (LMS) can be traced back to the 1990s, when it was known as the computer-based integrated learning system [1]. During the 1980 s, there were debates on the use of computers in education, when researchers, similar to now, conducted studies on effective learning systems. The use of computers was supported by the majority of scholars and teachers, but not by all, which led to continued debates. It was not until the 1990s that the World Wide Web, educational software, and personal computers placed computer-assisted pedagogy at the center of educational processes. These trends led to the development of LMSs.

The emergence of LMS has been traced by some researchers to rudimentary training management systems, which thereafter became platforms for e-learning [2].
Rudimentary training management systems were developed based on trial and error; the results of which were further used as the basis for computer learning systems. In teaching and learning, educational technology goes hand in hand with pedagogy. As such, LMS, a software designed to assist administrative activities and facilitate how the students participate in e-learning materials, was developed. The software application is used in tailoring content, e-learning programs, classroom and online events, tracking and reporting online programs, and documentation.

LMSs connect the students or learners with the learning contents in a standardized manner through software and programs specifically developed for student learning. They manage learning events, contents, and learners and administer and manage the learning processes and the performance of the learners by means of recording the activities on the computers and displaying statistics and plans. Often, the term "LMS" is used interchangeably with the "course management system" [2]. The creation of learning resources, delivering content to the students, monitoring students' participation, and assessing their performance are tasks that are highly dependent on LMSs [3]. Research shows that there is a need to centralize university processes and create a sense 
of uniformity among the universities [4]. Consequently, LMSs had to be implemented in many learning facilities. The new directions of these software applications included the educational focus on economic goals rather than social goals and discourse of free market competition.

\section{Background and LMS Characteristics}

LMSs are an e-learning online system in the form of a portal wherein students and lecturers can perform or share many of the classroom activities using the Internet; lecturers and students are able to interact outside the classroom through online forums and discussions more easily, as opposed to learning in a real classroom [5]. Given that the world has become a global village due to advancements in information and technology, Saudi Arabia has not been left behind in terms of Internet availability. Internet access for the students and lecturers has become an easy thing, therefore motivating the use of LMSs.

The Internet and intranet have brought about many changes in instructor/student interactions. This has enabled the communication process to change; the instructor does not have to communicate to the students only in the classrooms. LMSs are being used in institutions that are supported by good infrastructure, most popularly in developed countries. IMC (UK) Learning Ltd. published a report indicating that LMSs are being implemented by a large number of institutions in the United Kingdom. From the report, $66 \%$ of the respondents had already started to implement it, while $13 \%$ were looking forward to adopting the technology [2]. However, seven years have already passed since this research was conducted; hence, the numbers have changed. According to Alharbi and Drew, the adoption rate of LMSs in the US is more than $95 \%$ and more than $96 \%$ in the UK.

The software for the management of learning was developed to monitor the students' performance [7]. This means that there is an instructor who supervises the students' work and keeps track of their progress. According to Alghamdi and Bayaga [8], LMSs benefit not only the students but also the lecturers. The authors added that Saudi Arabian universities are facing an overcrowding problem. The use of information technology facilities can help resolve this issue by means of providing students with the course materials and other resources for individual learning [8]. The software has various advantages compared to traditional systems, which include ease of access, better communication, and increased relationships between students.

LMSs play a critical role in the higher education system because of the extension of the classroom and its activities online, hence connecting students to one another and to the lecturers [9]. This connection helps in online discussions and the sharing of learning materials, including textbooks, research materials, and other library resources. Software applications allow the instructors to teach using online tools, which the students use to contact other students and their lecturers [10]. Institutions with budget challenges prefer open LMS (also known as open-source LMS; hereafter OLMS) because it is cost-effective. OLMSs are set up so that any student can access them. An OLMS is designed to give its users the freedom to network with one another. Students using the OLMS can easily access learning resources and create educational links that would be beneficial for their studies [10]. The next generation of LMSs provides students with an improved user interface, branding, information system integration, and content sharing. Students can easily search for the required data and share it with other students [11]. Therefore, the online systems offer students more possibilities.

The tools and elements of LMSs include students' and teachers' functions and tools, communication tools, and learning material tools, as shown in the following:

(i) Learning materials include images, videos, and texts. They are provided to the students by the instructors, and students access and download them and can use them to discuss with one another.

(ii) The success of LMSs is ensured through collaborative and effective communication between the instructors and their students. Communication using the systems can be either synchronous or asynchronous. Synchronous communication is where participation occurs at the same time, while in asynchronous communication, participation does not occur at the same time; some examples are e-mail and discussion boards.

(iii) The instructor's functions and tools include course management tools, which help the teachers to upload course announcements, assessments, and learning materials. The instructor is able to plan the work for the entire course and send it to the students so that they can review the material before class, where they can instead discuss and ask questions about what they did not understand.

Students' functions enable the students to interact among themselves and with their instructors, and they are able to access learning materials that help them to carry out self-study. Therefore, students can read when they are free and discuss with others, even when they are far from each other, hence eliminating the need for classrooms.

LMSs do not replace traditional classroom systems, but they supplement the classroom with course content, which is accessed from the Internet. According to Bradford et al., the various educational software applications have substantially enhanced student motivation and have encouraged feedback. Currently, most learning facilities utilize the LMS as a tool for instruction delivery in traditional classroom setups. The software applications also lead to additional information being provided to students since they incorporate numerous learning resources that might not be available in traditional educational materials. Another key change that LMSs have brought to learning is the supplementation of traditional classrooms by enhancing research during class sessions. The advantages of supplementing the traditional classrooms with the LMS are quite clear. In addition, reactions of the students and instructors who are using the LMS are positive [13-15]. The attitudes of different 
members of an institution toward the use of LMSs are hypothesized to be context-specific and depend on sociocultural factors of the nation, the type of the LMS used, personal experiences of the members of the faculty, and the institution itself.

Typically, LMSs contain certain course elements that help administrators, teachers, and students source learning materials from online libraries. These systems are usually presented in a format of course catalogues with recorded data. The software is specifically used by the administration to manage documentation, track students' success, and report and deliver information about educational courses or training programs. Teachers use these systems to report students' grades and post news and additional materials for students to use. These systems are also used by the students in the forms of wikis, online forums, and discussions. Students also can view additional resources helpful in learning the material, observe announcements from teachers and administration, and follow the course content. Institutions use the LMSs to improve learning, therefore enhancing the performance of the learners [16]. Some organizations prefer using commercial LMSs, which require fees for their use but offer protection to their users [17]. However, institutions face constraints like pricing, suitability to the targeted groups, assessment tools, and linguistic challenges [18]. Open LMSs are free, while commercial ones are fee-based and have sophisticated features [17], which may have positive impact on the future of the LMS market. Commercial LMSs are easy to use; in case any issues arise, the support department is ready to help and the users' private data are better protected.

2.1. Justification. Little research has been done on the way students from Saudi Arabia perceive social networking and how they use it in the pedagogical practices [19]. The lack of research on social networking usage in Saudi Arabia is an indicator of the fact that the implementation of web technologies is not as advanced as it is in other nations [20]; there is a need for further investigation. There has also been little research done on Saudi Arabian social networking focusing on the barriers that universities face on the use of LMSs [8].

Saudi Arabian universities do not have much in the way of information and communication technology-supported learning resources despite the high use of information and communication technology (ICT) and social media in learning institutions internationally. Adoption of the Internet in Saudi Arabia began in the 1990s; universities were the first to adopt it, and later, the technology spread to all the campuses in the country. Developed countries like the United States are well known to use ICT in institutions with university degree programs. Use of ICT to support learning benefits both students and lecturers [21]. The use of ICT also helps in managing time, as students and the instructor can engage with each other both synchronously and asynchronously.

This paper will investigate the barriers that hinder the effective adoption and implementation of LMSs in different universities in Saudi Arabia and focus on the students' perspectives. This paper will attempt to answer the following question: What are the barriers to participation in LMSs in Saudi Arabian universities from the students' perspectives?

2.2. Literature Review. LMSs are a type of an ongoing infrastructure that many institutions globally are investing in. The most popular LMSs are Sakai, Desire2Learn, Moodle, and Blackboard. According to Zawaidy [22], Blackboard is the most commonly used system in Saudi Arabian institutions. However, some studies have shown that most of the Saudi Arabian institutions are not even aware of which type of LMS they use [23]. Watson and Watson [24] have confirmed the significance of the LMSs and their impact on teaching and learning variables, such as a positive trend on the teaching systems used by lecturers and the improvement in the performance of the students [24]. By using LMSs, students improve their English language performance. A study conducted by Wang and Chen [25] confirmed those results and further posited that, in language teaching, the use of synchronous LMSs helped to improve the performance of the students.

According to the study done by Kennedy [26], LMSs can be divided into two groups: closed source and open source. Open-source learning management can be modified and developed and is used free of charge. Examples of opensource LMSs include Moodle, ATutor, and Dokeos. Closedsource LMSs, on the other hand, are owned by private companies and used only by licensed users. These are also referred to as commercial LMSs, and some examples include WebCT and Blackboard.

The implementation of LMSs requires extensive evaluation as compared to other newer technologies, such as wikis and blogs. The in-depth evaluation is due to reimplementation costs that may arise due to poor initial choice. The use of LMSs establishes opportunities beyond cultural borders and helps in the distribution of education globally [2]. According to Kats, the distribution of education internationally can be hindered by barriers like the cultural diffusion of technology, language developments, or cultural norms. The author adds that when selecting an LMS, the institution should consider a platform in terms of robustness, affordability, adaptability, and the students' and faculty's profiles.

The need to provide a skilled educated workforce, the growth of the private sector, and the diversification of the economy are major contributions to the rising economic and social growth in Saudi Arabia [19]. According to the authors, Saudi Arabia is embarking on a type of education whereby investments are being made to bring higher education up to global standards. The Ministry of Education is aimed at enhancing the quality of education in the universities by using ICT initiatives and the potentiality of e-learning. Currently, the use of technologies by higher institutions in Saudi Arabia is sparse.

Despite the benefits of LMSs to Saudi Arabian university students, they also have major drawbacks that create barriers for easy and smooth utilization [19]. Some of these barriers are attributed to infrastructural issues, costs, cultural and moral discourse, the necessity of technical support and service for the students, and other various administrative barriers [8].

According to Issa et al. [19], teach management systems help in the reduction of data loss as all e-learning materials 
a student has will be stored in one location. Storing information online is much easier and efficient. A small amount of online storage, or any other storage facilities, is enough to store a large amount of data, as compared to hard copies, which consume more space. Alshahrani and Ally [5] also argued that books can get lost easily, and a student may end up losing information with no opportunity to recover it. Online storage, however, provides room for a backup; in case there is a loss of information, one can always get the information from a backup storage.

The benefits of LMSs have already been confirmed. However, some of these benefits are either limited or require significant effort in order to achieve them. The presence of specific barriers can create difficulties that prevent students and teachers from reaping the benefits of the systems. Poor Internet connectivity is a major barrier to students in Saudi Arabian universities [2, 27]. Given that LMSs only work online, the Internet is a necessity. Poor connectivity slows down learning processes and tampers with features such as online conferencing, which only work with strong networks.

Instructors' attitude toward students is also a barrier that affects the adoption of LMSs, such as when instructors are working with students who are not conversant with ICT usage [28]. Teachers do not consider LMSs' effective tools in teaching; instead, they utilize traditional strategies, which have been shown to be less efficient than innovative systems. For instance, instead of an instructor encouraging a student to use ICT in order to improve their knowledge, they demean the student or avoid helping them [28]. The author notes that this is a difficulty that most students face. In addition, some teachers also lack technological skills, inconveniencing the students.

Students who have been using the traditional way of learning in schools do face difficulties in adopting online systems [5]. This is attributed to the fact that students believe in face-to-face teaching; they have misconceptions about using the learning system. According to Alshahrani and Ally [5], many students feel that the traditional classroom style of learning is of higher quality in terms of interactions rather than checking the material in the LMS, thinking that an online facility cannot provide adequate data about the course; this has led to students not appreciating the LMS mode of learning.

Ioannou and Hannafin [29] (cited in [2]) reported that students complained that the LMS was confusing and slow, and it focused more on administration than on the students. The authors also added that students complained that the use of LMS interfaces was rigid and dull as compared to other social environments, like Facebook, YouTube, and MySpace, which are engaging and fun. Additionally, Pine et al. [30] (cited in [2]) mentioned that there was a lack of instructional design guidance and tools to develop the system into a rich, multimedia-based guide. Conversely, another study done by Dahlstrom et al. [31] reported that LMSs are intuitive, simplified, and user-friendly.

A research done by Smith and Abouammoh [23] reported that the main challenges of LMSs in Saudi Arabian institutions are a lack of or inadequate training and support, software issues that disrupt classroom teaching, blocked websites, and infrastructure failure in the universities. Other barriers that the authors reported include incompatibility of IT systems, poor management of technology implementation, and a lack of high-quality technical support staff. The study was not interested in a specific type of LMS. However, most universities had an OLMS.

\section{Materials and Methods}

3.1. Data Collection. We surveyed three universities that had different degrees of the LMS infrastructure. The three universities were highly ranked learning facilities with a large number of scholars; however, they had limited LMS adoption rates. Because our research methods relied on responses from many individuals, the large amount of available scholars was an asset for gathering information regarding barriers of LMSs in Saudi Arabian institutions.

The method of data collection used in this study involved a survey; questionnaires were administered online to all students who had agreed to take part in the study in three universities in Saudi Arabia. The questionnaires had a series of questions that were administered using Google Drive, which, unlike LMSs, is used daily by students in Saudi Arabia for a variety of purposes. Google Drive provides a platform whereby a single message can be broadcast to numerous recipients. This method of data collection was selected because it afforded flexibility to assess students from three different universities.

The questionnaires used an open-ended question format, so the participants could fill in their responses directly and in their own words. The authorized participants were contacted by e-mail with the information about the questionnaires. The questionnaires were sent as links by e-mail to all faculty members from all the campuses for review purposes. However, these faculty members did not play an active role in filling out the questionnaires. A total of 150 questionnaires were completed within six days, and the data were exported to Excel and saved. Students from all three universities actively participated in filling out the questionnaire, and only about $3 \%$ of the values were incomplete. One important flaw in the questionnaire was its failure to provide a criterion for self-assessment for computer skills and English proficiency. The questionnaire was subjective; participants' individual perceptions of the extent to which LMS has been implemented in their universities is one of the key pieces of information that this study aimed to explore. No specific LMS types were selected for the study.

3.2. Survey Instrument. The survey instrument used in this study was designed by the authors. The main section required the students to indicate their use, attitudes, and barriers toward LMSs. A 4-point Likert scale was used, whereby the students rated their responses as poor, fair, good, and very good. The topics of the questions were the following:

(i) The level of access and restrictions of LMS resources

(ii) Internet access and networking 
TABle 1: Participant characteristics.

\begin{tabular}{lcc}
\hline Variables & Number & Percentage \\
\hline \multirow{2}{*}{ Gender } & 98 females & 65.3 \\
& 52 males & 34.7 \\
\hline \multirow{2}{*}{ Qualifications } & 144 bachelor's degree & 96 \\
& 6 master's degree & 4 \\
\hline \multirow{2}{*}{ Computer skills } & 7 advanced & 4.7 \\
& 140 intermediate & 93.3 \\
\multirow{2}{*}{ Age } & 3 beginners & 2 \\
\hline \multirow{3}{*}{ English proficiency } & 146 under 30 years & 97.3 \\
& 4 over 30 years & 2.7 \\
\hline \multirow{2}{*}{ Attitude toward LMS } & 13 excellent & 9 \\
& 59 advanced & 40 \\
& 50 above average & 33 \\
& 28 average & 18 \\
\hline \multirow{2}{*}{. 138 positive } & 92 \\
\end{tabular}

(iii) Training on LMSs

(iv) Role models

(v) Security concerns

(vi) Availability of hardware and software

(vii) English language proficiency (important for understanding the LMS, which is in English)

The questionnaire had five subsections:

(i) Qualifications of the students and their computer skills

(ii) Personal experiences with using LMSs in the student's campus, age of the student, and attitude toward the LMS

(iii) LMS that is used in the campus

(iv) Availability of the preferred LMS training courses

(v) The use and attitude toward preferred LMSs

\section{Results and Discussion}

The research was conducted among 98 women and 52 men. Most of the participants were pursuing bachelor's degrees (96\%), and only $4 \%$ of respondents were pursuing master's degrees. All of the respondents had some level of computer skills: 140 assessed their level as intermediate, 7 considered them to be advanced, and 3 participants were beginners. Most of the participants (97.3\%) were under 30 years, and $4 \%$ were over 30 . The least number of the participants expressed excellent English proficiency (9\%), most of the participants (40\%) reported advanced skills, 33\% reported above-average proficiency, and $18 \%$ reported average skills. The most important finding in the research was that 138 students (92\% of the participants) had positive attitude about using the LMS.

Table 1 provides the participant characteristics.

The survey results related to the research questions identified that only $13 \%$ (20 respondents) of the respondents had free access to LMS resources, while others (130 respondents) were restricted in this access, either physically or because of significant time restrictions. Most of the respondents, 113 students (76\%), had access to the Internet in the campus, but all of them complained about its slow speed or constant drop of connection. In addition, $100 \%$ of students confirmed that they had adequate hardware to use the LMSs. Apart from some attempts at implementing LMSs in the classroom (25\%), none of the students reported on adequate training of how to use the LMS. In addition, none of the students reported on the presence of role models to follow with respect to using LMSs. Out of the respondents, $68 \%$ were concerned about security issues (Table 2). These are some of the important barriers to successfully implementing LMSs in Saudi Arabian universities.

Another factor that influenced the use of LMS resources, which was considered a barrier to implementation, was the level of support from the university. Most of the respondents (99 subjects) reported poor support. Twenty-five and 21 respondents reported fair and good levels of support, respectively, and only 5 subjects were satisfied with the level of the support from the university. The research findings also indicated that the university's infrastructure was not a barrier to implementing LMSs because most of the respondents considered it either good (79 subjects) or very good (43 subjects). Only three respondents believed that the infrastructure of the university was poor enough to hinder the LMS.

A high level of availability of computers in the campus could be helpful to the implementation of LMSs in the universities. None of the students reported on poor computer access in the schools; as a result, this factor was eliminated from the possible barriers (Table 2). It is possible to conclude that the universities under consideration all had the chance to implement the LMS; the real barriers students indicated could be improved with minimum costs.

The results of the questionnaire were considered with the purpose to identify the possible barriers to implementing the LMS in the universities and how students view them. The results will be discussed in the next section, and final conclusions will be drawn to highlight the main barriers to implementing LMSs in Saudi Arabian higher educational establishments from the perspectives of the students of three different universities.

The analysis of the literature and the findings from the questionnaire allow us to draw conclusions about the contemporary level of knowledge of students regarding LMSs and their vision of the application of the system in the selected universities. Here, we will also identify the gaps in the field of knowledge for further research and discussion for future studies.

Out of the 150 students from the three universities selected in Saudi Arabia, many students were aware of and likely had used an LMS. A high level of computer proficiency among students in our study indicates that only a few students might face difficulties in this regard when using the LMS. Even though students in this study did not receive any training on the use of LMSs, they still had access to the resource and were ready to use it if universities would provide training. The research findings also showed that students had positive attitude about using the LMS in class.

However, this result contradicts the research findings obtained from the literature review, which identified the top 
TABLE 2: Analysis of barriers to the student's use of LMSs.

\begin{tabular}{|c|c|c|c|c|}
\hline Students' barrier factors & Poor & Fair & Good & Very good \\
\hline $\begin{array}{l}\text { What is the attitude of students toward new } \\
\text { technology? }\end{array}$ & 7 & 18 & 91 & 34 \\
\hline What is the level of support from the university? & 99 & 25 & 21 & 5 \\
\hline How are students trained on the use of LMSs? & 150 & 0 & 0 & 0 \\
\hline $\begin{array}{l}\text { What kind of infrastructure support does the } \\
\text { university have? }\end{array}$ & 3 & 25 & 79 & 43 \\
\hline How is the university's Internet access? & 85 & 35 & 27 & 3 \\
\hline What is the availability of computers at the school? & 0 & 16 & 115 & 19 \\
\hline $\begin{array}{l}\text { What is the student's mastery of the English } \\
\text { language? }\end{array}$ & 11 & 65 & 66 & 8 \\
\hline
\end{tabular}

TABLE 3: Comparative analysis of the barriers of using LMSs between the literature review and the questionnaire results.

\begin{tabular}{|c|c|c|}
\hline Barrier & Literature review & Qualitative study \\
\hline Negative attitude toward new technology & $\checkmark$ & \\
\hline Lack of technical support from the institutions & $\checkmark$ & \\
\hline Lack of training on LMSs & $\checkmark$ & $\checkmark$ \\
\hline $\begin{array}{l}\text { Poor Internet access and networking in the } \\
\text { institutions }\end{array}$ & $\checkmark$ & $\checkmark$ \\
\hline Inadequate availability of software and hardware & $\checkmark$ & \\
\hline Infrastructure failure & $\checkmark$ & \\
\hline $\begin{array}{l}\text { Lack of time by the instructors to guide the students } \\
\text { on how to use LMSs }\end{array}$ & $\checkmark$ & \\
\hline
\end{tabular}

barriers to implementation. Previous reports showed that a number of students had negative attitude toward new technology, a lack of technical support from the institutions, and a lack of training on LMSs. Despite the fact that our research results confirmed poor Internet connections, all of the students confirmed that they had enough resources for utilizing LMSs in their universities. Moreover, students were encouraged and positively directed toward the use of technology, which rejected the findings indicated in the literature review. However, the research findings did confirm a lack of training, which was the main barrier to successfully implementing LMSs. In summary, the results confirm that indeed, there exist numerous barriers to participation in LMS in the higher learning facilities in Saudi Arabia as demonstrated by the three learning facilities explored. Therefore, the results disprove the findings of most of the reviewed literature.

Other barriers that were noted in the literature review included poor Internet access and networking in the institutions, inadequate availability of software and hardware, and infrastructure failure, as well as lack of time by the instructors to guide the students on how to use LMSs. However, our study contradicted many of these points. The universities from our study had enough software and hardware and provided adequate access to the Internet and networking, although there were remarks on poor connections and slow speeds. Our research findings also supported the absence of training on the use of LMSs. The results confirm that students have enough background knowledge and skills in computer proficiency to use the LMS, but barriers inherent in the university infrastructure and faculty attention complicate their use of knowledge to its full potential and create difficulties for obtaining quality training. The comparative analysis of the literature review and our qualitative findings on the barriers to implementing LMSs in the universities is provided in Table 3.

The adoption of LMSs in learning institutions has numerous benefits [15]. However, some universities have not yet been able to adopt the system because of the presence of a variety of barriers. From the students' perspectives, our study shows that it is evident that the students are willing to use the LMS, but due to some barriers, they are not in a position to use it. Internet access is a key factor for using the LMS, and poor Internet access would hamper the students' use of the system. The students should also be trained on the use of the system. A lack of training causes low motivation among the students, hindering their use of the system. Hardware and software issues should be considered by the institutions to ensure that the LMS can be accessed at all times by the students.

A lack of technical support by the universities on the use of LMSs has affected the adoption by Saudi Arabian institutions [32]. Selim [33] reported that it is the institution's role to support advancements in technology, and universities should ensure that they have the needed equipment and other access tools that users need. All LMSs have similar characteristics and function in the same way, although some have fewer tools than others [26].

4.1. Implications of Findings. Despite the positive attitude that the students within the three learning facilities have developed toward new technology, the lack of adequate support from the university and poor accessibility to Internet negatively affect networking in institutions. None of 
the facilities train students on how to use the LMS for educational purposes, implying that universities disregard the relevance of such systems. However, the high availability of computers and the presence of infrastructure in schools imply that learning institutions are catching up with the technological trends witnessed in Western countries.

\section{Conclusions}

In the new world of technology, information is shared quickly through the use of the Internet. If Saudi Arabia aspires to have institutions that perform highly on a global level, then it must invest in skilled human resources, infrastructure, and technology. LMSs are important tools that can be adopted by universities to help Saudi Arabian students have a higher-quality educational experience; they can help students in their learning and stay updated on their coursework. Instructors' work is also made easier, since they can reach out to their students outside of class hours and update them about the coursework using the system. LMSs offer other benefits as well, such as being able to easily access the school management system and monitor the performance.

To increase the quality and improve the performance of students in universities, LMSs should be considered as a means of complementing the formal education system. LMSs support the instructors and their students by creating a collaborative environment wherein the students interact among themselves and with their lecturers. Institutions should identify their needs so that they can consider the functionality of LMSs before investing in them.

Barriers to implementing the use of LMSs and ways to overcome them should be identified in order to ensure that all institutions are able to adopt a system to improve the performance of students. Because this is a new system to students, some who use the LMSs will encounter challenges; hence, the institution should provide adequate training to users. Technical support should also be provided to the students so that they are trained on how to use the system to access information and upload their assignments.

This paper has mainly focused on the barriers to implementing LMSs. Previous research has shown that LMSs offer advantages, and from this paper, it is clear that university students are willing to adopt the LMS, but due to some barriers, they are not able to implement it. Higher education institutions should consider LMSs as a complement to the traditional mode of learning and a way to improve the performance of students.

\section{Data Availability}

All available data supporting these findings are available at the E-Journal Publishing Database (doi: 10.7763/ijiet.2016. v6.652).

\section{Conflicts of Interest}

The authors declare that there are no conflicts of interest regarding the publication of this paper.

\section{Acknowledgments}

The author expresses his gratitude to everyone who supported him throughout the course of this research. The author would like to thank all of the participants in the study-students, academic staff, and authorities of universities-for the time and help given throughout the study.

\section{References}

[1] H. J. Becker and N. Hativa, "History, theory and research concerning integrated learning systems," International Journal of Educational Research, vol. 21, no. 1, pp. 5-12, 1994.

[2] Y. Kats, Learning Management System Technologies and Software Solutions for Online Teaching: Tools and Applications, Information Science Reference, Hershey, PA, USA, 2010.

[3] Information Science Reference, Information Resources Management Association Virtual Learning Environments: Concepts, Methodologies, Tools and Applications, Information Science Reference, Hershey, PA, USA, 2012.

[4] D. Markwell, Improving Teaching and Learning in Universities, Business Higher Education Round Table, vol. 1, no. 18, pp. 1-40, 2003, https://www.bhert.com/publications/newsletter/ B-HERTNEWS18.pdf.

[5] K. Alshahrani and M. Ally, Transforming Education in the Gulf Region: Emerging Learning Technologies and Innovative Pedagogy for the 21st Century, Routledge, London, UK, 2016.

[6] S. Alharbi and S. Drew, "Using the technology acceptance model in understanding academics' behavioural intention to use learning management systems," International Journal of Advanced Computer Science and Applications, vol. 5, no. 1, pp. 143-155, 2014.

[7] P. Moses, W. Z. W. Ali, and S. E. Krauss, "Cause analysis of learning management system: role of moderator in improving students' performance," Research and Practice in Technology Enhanced Learning, vol. 9, no. 1, pp. 83-105, 2014.

[8] S. R. Alghamdi and A. Bayaga, "Use and attitude towards learning management systems (LMS) in Saudi Arabian universities," Eurasia Journal of Mathematics, Science and Technology Education, vol. 12, no. 9, pp. 2309-2330, 2016.

[9] N. A. Adzharuddin and L. H. Ling, "Learning management systems (LMS) among university students: does it work?," International Journal of e-Education, e-Business, e-Management and e-Learning, vol. 3, no. 3, pp. 248-252, 2013.

[10] S. Lonn and S. D. Teasley, "Saving time or innovating practice: investigating perceptions and uses of learning management systems," Computers and Education, vol. 53, pp. 686-694, 2009.

[11] A. A. Sejzi and B. Aris, "Learning management system (LMS) and learning content management system (LCMS) at a virtual university," in Proceedings of the 2nd International Seminar on Quality and Affordable Education, vol. 2, pp. 216-220, Johor, Malaysia, October 2013.

[12] P. Bradford, M. Porciello, N. Balkon, and D. Backus, "The Blackboard Learning System: The Be All and End All in educational instruction?," Journal of Educational Technology Systems, vol. 35, no. 3, pp. 301-314, 2007.

[13] N. Emelyanova and E. Voronina, "Introducing a learning management system at a Russian university: students' and teachers' perceptions," International Review of Research in Open and Distributed Learning, vol. 15, no. 1, 2014.

[14] S. B. Eom, "Understanding e-learners' satisfaction with learning management systems," Bulletin of the IEEE Technical 
Committee on Learning Technology, vol. 16, no. 2-3, pp. 10-13, 2014.

[15] N. Sayfouri, "Evaluation of the learning management system using students' perceptions," Medical Journal of the Islamic Republic of Iran, vol. 30, p. 460, 2016.

[16] S. Thuseethan, S. Achchuthan, and S. Kuhanesan, "Usability evaluation of learning management systems in Sri Lankan universities," Global Journal of Computer Science and Technology, vol. 15, no. 1, pp. 1-13, 2015.

[17] H. L. Grob, F. Bensberg, and B. L. Dewanto, "Developing, deploying, using and evaluating an open source learning management system," Journal of Computing and Information Technology, vol. 12, no. 2, pp. 127-134, 2004.

[18] M. F. Paulsen, "Experiences with learning management systems in 113 European institutions," Educational Technology and Society, vol. 6, no. 4, pp. 134-148, 2003.

[19] T. Issa, P. Isaias, and P. Kommers, Social Networking and Education: Global Perspectives, Springer, New York, NY, USA, 2015.

[20] M. T. Simsim, "Internet usage and user preferences in Saudi Arabia," Journal of King Saud University-Engineering Sciences, vol. 23, no. 2, pp. 101-107, 2011.

[21] A. Sangrà and M. González-Sanmamed, "The role of information and communication technologies in improving teaching and learning processes in primary and secondary schools," Research in Learning Technology, vol. 18, no. 3, pp. 207-220, 2010.

[22] H. A. Z. H. E. Zawaidy, "Using Blackboard in online learning at Saudi universities: faculty member's perceptions and existing obstacles," International Interdisciplinary Journal of Education, vol. 3, no. 7, pp. 142-150, 2014.

[23] L. Smith and A. Abouammoh, Higher Education in Saudi Arabia: Achievements, Challenges, and Opportunities, Springer, Dordrecht, Netherlands, 2013.

[24] W. R. Watson and S. L. Watson, "An argument for clarity: what are learning management systems, what are they not, and what should they become?," TechTrends, vol. 51, no. 2, pp. 28-34, 2007.

[25] Y. Wang and N. Chen, "Criteria for evaluating synchronous learning management systems: argument from the distance language classrooms," Computer Assisted Language Learning, vol. 22 , no. 1, pp. 1-18, 2009.

[26] D. J. Kennedy, "Virtual learning environments (VLEs): here to stay, or on the brink of demise?," Plymouth Student Educator, vol. 1, no. 1, pp. 58-56, 2009.

[27] M. J. S. Asiri, E. S. Bakadam, K. Abu Bakar, R. Mahmud, and A. F. B. M. Ayub, "Barriers of using Jusur Learning Management System in Saudi Arabia universities," Journal of Research in Curriculum, Instruction and Educational Technology, vol. 1, no. 4, pp. 49-62, 2015.

[28] L. Kyei-Blankson, E. Ntuli, and H. Donnelly, "Establishing the importance of interaction and presence to student learning in online environments," World Journal of Educational Research, vol. 3, no. 1, pp. 48-65, 2016.

[29] A. Ioannou and R. Hannafin, "Deficiencies of course management systems: do students care?," Quarterly Review of Distance Education, vol. 9, no. 4, pp. 415-425, 2008.

[30] A. Pine, S. Green, and M. Eggers, "Learning management system: lessons from the front lines," in Proceedings of Paper presented at the Annual Technology in Education (Tec Ed) Conference, Ontario, CA, USA, 2008.

[31] E. Dahlstrom, D. C. Brooks, and J. Bichsel, "The current ecosystem of learning management systems in higher education: student, faculty, and IT perspectives," Research Report,
ECAR, Louisville, CO, USA, 2014, http://www.educause.edu/ ecar.

[32] H. B. Hussein, "Attitudes of Saudi universities faculty members towards using learning management system (JUSUR)," Turkish Online Journal of Educational Technology, vol. 10, no. 2, pp. 43-53, 2007.

[33] H. M. Selim, "Critical success factors for e-learning acceptance: confirmatory factor models," Computers and Education, vol. 49, no. 2, pp. 894-905, 2007. 


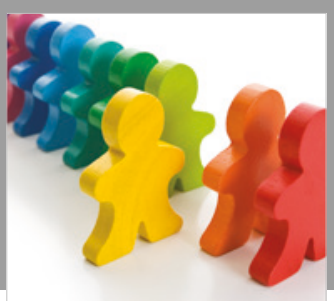

Autism

Research and Treatment
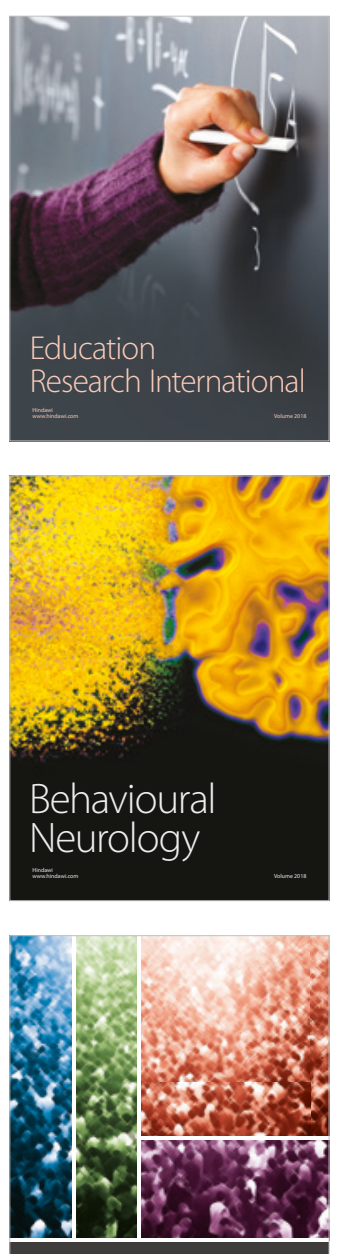

International Journal of

Population Research

$\underline{-m}$

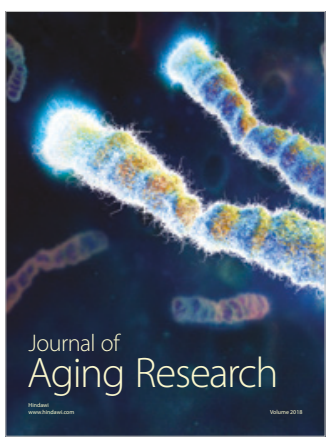

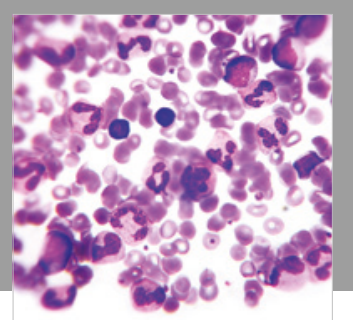

Pathology

Research International$$
=
$$

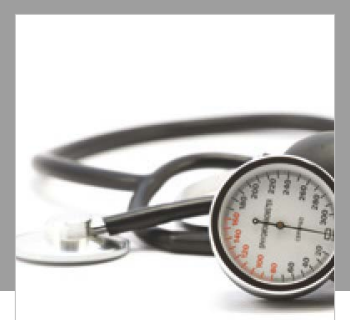

Nursing

Research and Practice

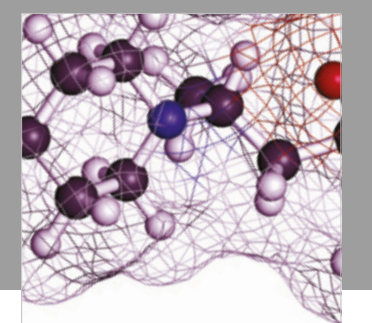

Pain

Research and Management

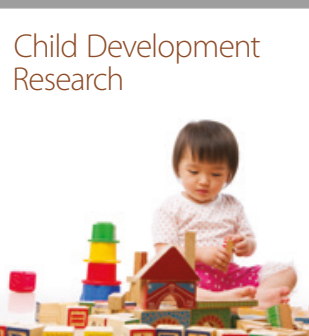

बाD

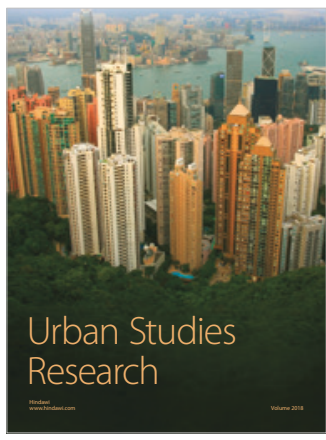

\section{Hindawi}

Submit your manuscripts at

www.hindawi.com
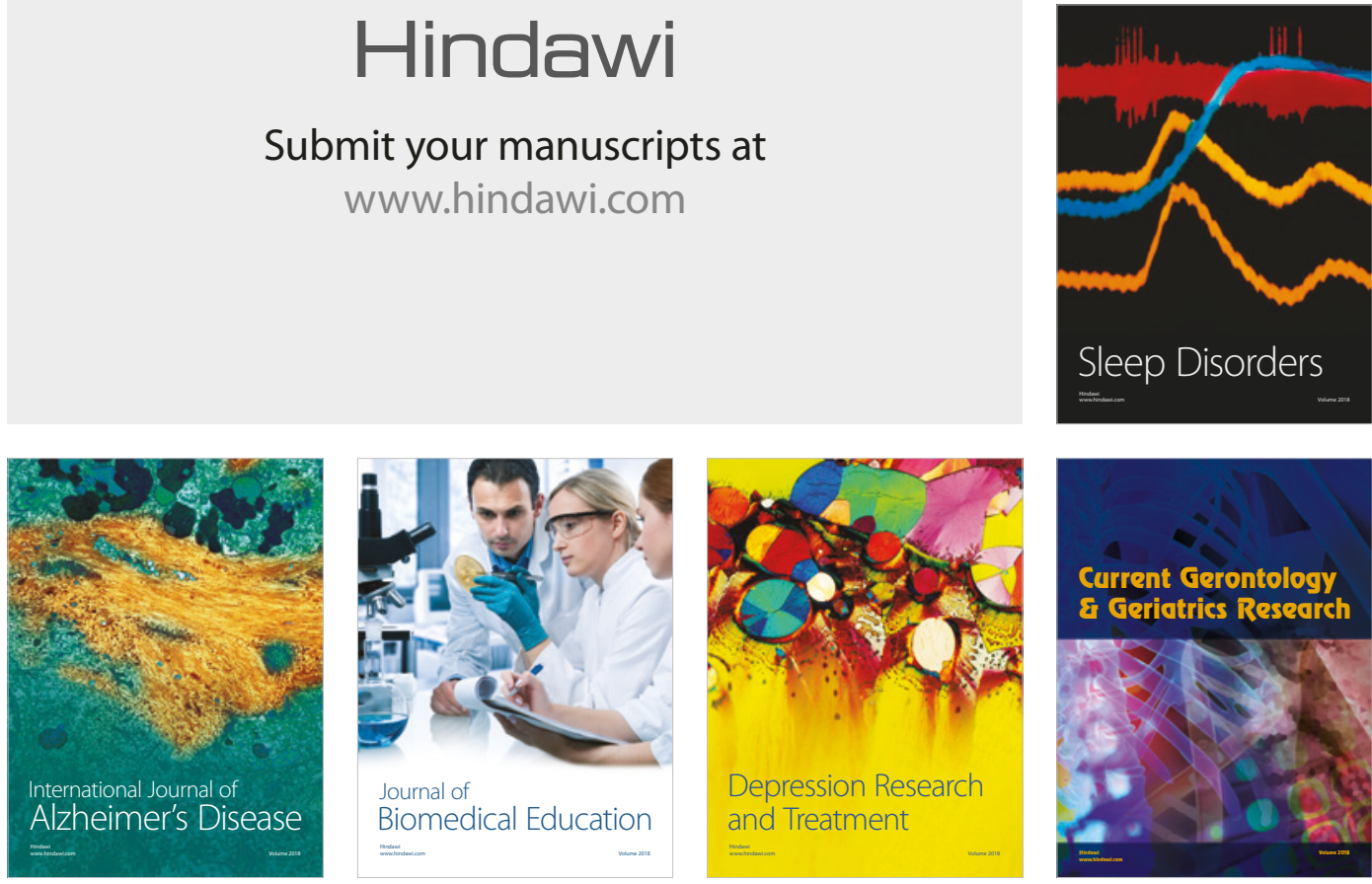

Journal of

Biomedical Education

$=$

smman

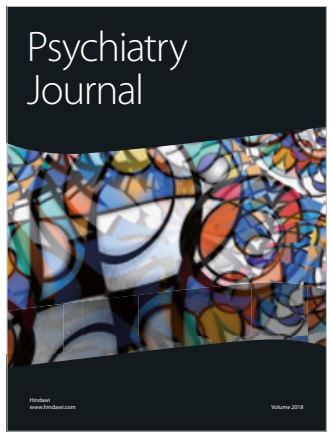

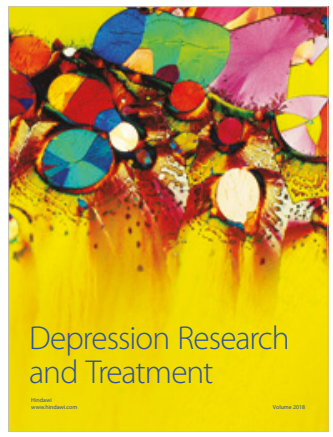
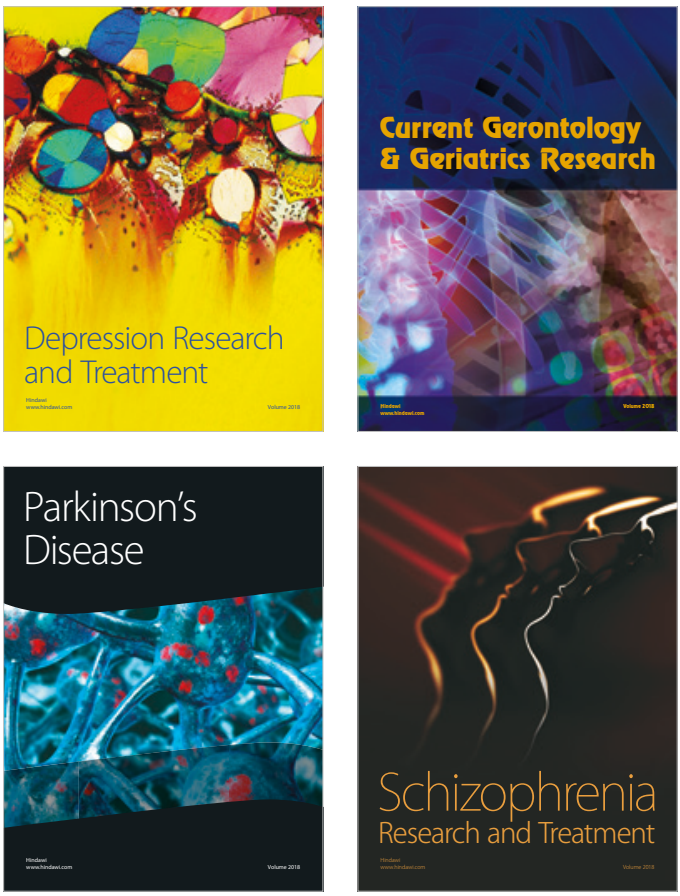